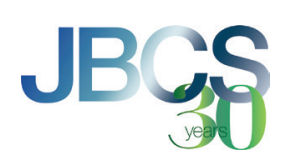

http://dx.doi.org/10.21577/0103-5053.20190046

J. Braz. Chem. Soc., Vol. 30, No. 7, 1498-1505, 2019

\title{
Determination of Antibiotics Residues in Milk Using a QuEChERS Method Using Full Factorial Design and Liquid Chromatography-Tandem Mass Spectrometry
}

\author{
Andressa H. A. Grabsk, ${ }^{a}$ João Raul B. de Souza, ${ }^{a}$ Francilaine E. De Marchi, ${ }^{b}$ \\ Rodolpho M. do Prado, ${ }^{a}$ Geraldo T. dos Santos, ${ }^{b}$ Carla Porto ${ }^{c}$ and Eduardo J. Pilau ${ }^{\circledR *, a}$ \\ ${ }^{a}$ Laboratório de Biomoléculas e Espectrometria de Massas (LaBioMass), Departamento de Química (DQI), \\ Universidade Estadual de Maringá, 87020-900 Maringá-PR, Brazil \\ ${ }^{b}$ Núcleo de Pesquisa e Estudo em Pecuária Leiteira (NUPEL), Departamento de Zootecnia (DZO), \\ Universidade Estadual de Maringá, 87020-900 Maringá-PR, Brazil
}

'Mestrado em Ciência, Tecnologia e Segurança Alimentar, Instituto Cesumar de Ciência, Tecnologia e Inovação (ICETI), Centro Universitário de Maringá (UniCesumar), Av. Guedner, 1610, 87050-900 Maringá-PR, Brazil

\begin{abstract}
This study evaluated different methods of extraction based on quick, easy, cheap, effective, rugged and safe (QuEChERS) method for analysis of the antibiotics ceftiofur, cloxacillin and enrofloxacin in milk using ultra-performance liquid chromatography-tandem mass spectrometry. The QuEChERS acetate method has been shown to be inefficient for extracting such antibiotics. The optimized QuEChERS method presented excellent recoveries, from 95 to $99 \%$. A complete factorial design was used to evaluate the effects of variables of the clean-up step: anhydrous octadecylsilane (C18), primary secondary amine (PSA) and sodium acetate $(\mathrm{NaAc})$. Linearity $\left(\mathrm{R}^{2}\right)$ above 0.96 was achieved for all compounds. Accuracy and precision were assessed by recovery. Accuracy was 91-99\%. Intraday precision with relative standard deviations (RSD) lower than $12.3 \%$ and interday precision lower than $12.4 \%$ were obtained. Limits of detection (LOD) and quantification (LOQ) were obtained between 1.4-6.8 and 1.5-8.7 $\mu \mathrm{g} \mathrm{\textrm {L } ^ { - 1 }}$, respectively. The applicability was evaluated using 91 real milk samples.
\end{abstract}

Keywords: enrofloxacin, cloxacillin, ceftiofur, cow milk, UPLC-MS/MS

\section{Introduction}

Antimicrobial resistance is a major global threat with human mortality rates of 10 million per year predicted by $2050 .{ }^{1}$ Increasing incidence of antimicrobial resistance is largely attributed to intensive use of antibiotics for humans and livestock production. ${ }^{2}$ Close to two-thirds of the global production of antibiotics is attributed to agricultural use, ${ }^{3}$ where antibiotics are mainly used in livestock production to control infectious and common diseases, and to enhance animal growth. ${ }^{4}$ The antibiotic prescription and the intensive use can result on persistence of antibiotics residues (ARs) in biologic tissues and fluids of animals, and the inappropriate consumption can promote antimicrobial resistance, may also interfere with fermented milk product processing. ${ }^{2}$ Moreover, the presence of ARs in livestock products may affect human health and interfere with industrial processes. For example, there is evidence that ARs affects the growth of desirable

*e-mail: epilau@gmail.com bacteria for cheese production or dairy beverages. ${ }^{5}$ Thus, maximum residue limits (MRLs) for various veterinary drugs in foods, milk included, are established by governmental agencies. Each antibiotic has a MRL considered safe, above which there is potential to cause harm to human health. ${ }^{6}$ However, extraction of ARs for analysis in milk is challenging due to the complex nature of milk, which is a matrix enriched in fats, sugars and proteins. ${ }^{7}$

Anastassiades and Lehotay ${ }^{8}$ proposed an extraction method for the simultaneous analysis of pesticides in various agricultural food matrices, which was termed as QuEChERS (quick, easy, cheap, effective, rugged and safe).

This method is based on the difference of affinities between reagents and analytes in a liquid-liquid extract improved by salting out effect. For cleaning purposes, dispersive solid phase extraction (d-SPE) is the most relevant, in which different sorbents with different affinities are used for specific analytes. ${ }^{9}$ Yet, modifications of the QuEChERS acetate method, described by Lehotay et al. ${ }^{10}$ were proposed to consider nature of the analytes and 
matrices. The authors added octadecylsilane (C18) to the usual sorbents in the clean-up step to improve extraction on high fat food matrices, such as milk, eggs, avocado and animal tissues. More recently, used sodium sulfate $\left(\mathrm{Na}_{2} \mathrm{SO}_{4}\right)$ as the drying reagent, and the reagents $\mathrm{C} 18$, primary secondary amine (PSA), and sodium acetate for the cleanup step for multiresidue analysis of antibiotics in milk.

Among the antibiotics most used by producers of dairy cattle in the northern region of Paraná are enrofloxacin (ENRO), ceftiofur (CEFT) and cloxacillin (CLOX) (data not shown). Enrofloxacin is a fluoroquinolone, nalidixic acid derivative with broad-spectrum activity against Gram-negative bacteria. Ceftiofur is a cephalosporin semisynthetic antibiotic, a class of $\beta$-lactams, and it has activity against both Gram-positive and Gram-negative bacteria. Cloxacillin is a $\beta$-lactam antibiotic of the penicillin group. ${ }^{11}$ Brazilian milk production was 33.7 billion liters in 2016, the Southern Region participated with 12.5 billion liters $(37.1 \%)$, the largest producing region of the country. The state of Paraná produced 4.730 billion and increased $1.5 \%$ compared to $2015 .{ }^{12}$ The acquisition of raw milk in the first quarter of 2018 was 6.10 billion liters, $4.1 \%$ higher than in the first quarter of $2017 .{ }^{13}$ Studies aimed at improving animal welfare, reducing somatic cell counts, improving cow health and minimizing waste management expenses are constantly being developed to that milk production in these regions will grow to face competition from the world market. ${ }^{14}$

The development and optimization of analytical methods is laborious and resource-consuming. Thus, the use of statistical methods and the experimental design for systematic optimization (e.g., factorial design and response surface analysis) can be applied to different systems. ${ }^{15}$ The advantage of such approaches is that they provide more information about the variables and their interactions with fewer experiments compared to traditional univariate studies. ${ }^{16}$ Full factorial design is a statistical multivariate optimization, which is widely applied to identify significant variables and the best conditions of an experiment. ${ }^{17}$

The objective of this research was to optimize and develop a high throughput method for routine analysis to detect trace levels of three major ARs in whole milk (ENRO, CEFT and CLOX) using the QuEChERS acetate ${ }^{10}$ and modified QuEChERS ${ }^{18}$ methods. Furthermore, experimental design was used to optimize the conditions used for sample preparation. Finally, the optimized method was used to evaluated the three ARs on 91 bulk samples of dairy cattle milk from the north region of the State of Paraná, Brazil.

\section{Experimental}

\section{Chemical and reagents}

Ceftiofur (purity $\geq 95.0 \%$ ), cloxacillin (purity $\geq 98.0 \%$ ) and enrofloxacin (purity $\geq 98.0 \%$ ) were purchased from Sigma-Aldrich (St. Louis, USA). Acetonitrile (ACN), glacial acetic acid and methanol from Panreac AppliChem (Darmstadt, Germany) were purchased high-performance liquid chromatography (HPLC) grade. Formic acid (98\%) from Panreac AppliChem (Darmstadt, Germany, grade PA), anhydrous sodium sulfate $\left(\mathrm{Na}_{2} \mathrm{SO}_{4}\right)$, anhydrous sulfate magnesium $\left(\mathrm{MgSO}_{4}\right)$ from Fmaia (São Paulo, Brazil) and anhydrous sodium acetate $(\mathrm{NaAc})$ from Dynamics (São Paulo, Brazil), were of analytical grade. Ultrapure water was purchased with Gehaka water purification system, model OS10LXE (Curitiba, Brazil). Octadecylsilane (C18) and secondary primary amine (PSA) were obtained from Sigma-Aldrich (St. Louis, USA).

\section{Preparation of standards}

Stock standard solutions were prepared at concentration of $1.0 \mathrm{mg} \mathrm{mL}^{-1}$, using ethanol (97\%) with CEFT; ultrapure water with CLOX; and methanol with ENRO. Diluted working solutions were prepared using ultrapure water at concentrations of 1.0 to $50.0 \mu \mathrm{g} \mathrm{mL}^{-1}$. Stock and diluted solutions were prepared monthly and stored at $-20{ }^{\circ} \mathrm{C}$.

Milk samples

Pasteurized dairy milk samples obtained from local supermarkets (Maringá city, Brazil) were used for the validation. For the study of validation, dairy milk samples were first analyzed by ultra-performance liquid chromatography-tandem mass spectrometry (UPLC-MS/MS) to verify the absence of the studied antibiotics. After that, known concentrations of standards were added to the milk samples. For the study of occurrence of AR in Paraná, dairy milk samples were sampled from bulk milk tanks from various dairy farms in Paraná State, Brazil. The quantification was performed by external calibration by matrix overlap.

\section{Sample extraction-QuEChERS acetate}

CEFT, CLOX and ENRO were extracted from spiked milk samples according to Lehotay et al..$^{10}$ Briefly, $15.0 \mathrm{~mL}$ of spiked milk was mixed with $15.0 \mathrm{~mL}$ of the extraction solvent (ACN with $1 \%$ acetic acid v:v), $6.0 \mathrm{~g}$ anhydrous $\mathrm{MgSO}_{4}$ and $1.5 \mathrm{~g}$ anhydrous $\mathrm{NaAc}$, and shaken by hand 
vigorously for $1 \mathrm{~min}$. The volume was centrifuged for $10 \mathrm{~min}$ at $6,000 \mathrm{rpm}$ at $4{ }^{\circ} \mathrm{C}$. An aliquot of $1 \mathrm{~mL}$ of the ACN supernatant was transferred to a $2.0 \mathrm{~mL}$ microfuge tube for the d-SPE (containing 50.0 mg PSA + 50.0 mg C18 + $150.0 \mathrm{mg}$ anhydrous $\mathrm{MgSO}_{4}$ ). The tube was vortexed for $20 \mathrm{~s}$ and centrifuged. The aliquot was filtered and transferred to an auto sampler vial for UPLC-MS/MS analysis.

\section{Sample extraction-modified QuEChERS}

CEFT, CLOX and ENRO were also extracted from spiked milk samples according to Wang et al..$^{18}$ Briefly, $10.00 \mathrm{~mL}$ of spiked milk was mixed with $10.0 \mathrm{~mL}$ of the extraction solvent (ACN with $1 \%$ acetic acid; v:v) and $6.0 \mathrm{~g}$ of anhydrous $\mathrm{Na}_{2} \mathrm{SO}_{4}$, and the volume was vortexed for $2 \mathrm{~min}$. The volume was centrifuged for $10 \mathrm{~min}$ at $6,000 \mathrm{rpm}$ at $4{ }^{\circ} \mathrm{C}$. The ACN layer was transferred to volumetric flask of $25 \mathrm{~mL} .10 .0 \mathrm{~mL}$ of ACN with $1 \%$ ammonium hydroxide was added to the remaining tube and vortexed for $2 \mathrm{~min}$. The volume was centrifuged for $10 \mathrm{~min}$ at $6,000 \mathrm{rpm}$ at $4{ }^{\circ} \mathrm{C}$. The ACN layers were transferred to flask of $25 \mathrm{~mL}$ and diluted with ACN to a volume of $25 \mathrm{~mL}$. An aliquot of $5.0 \mathrm{~mL}$ top layer extract was transferred to a $15 \mathrm{~mL}$ vial and added C18, PSA, and anhydrous $\mathrm{NaAc}(100.0 \mathrm{mg}, 50.0 \mathrm{mg}$ and $1.0 \mathrm{~g}$, respectively) to the extraction solution. The tube was vortexed for $2 \mathrm{~min}$ and centrifuged for $10 \mathrm{~min}$ at $6,000 \mathrm{rpm}$ at $4{ }^{\circ} \mathrm{C}$. All the supernatant of the aliquot was evaporated to dryness on a vaccum-rotary evaporator and $2.0 \mathrm{~mL}$ of water/ACN solution (95:5/v:v, with $0.1 \%$ acetic acid) was added and vortexed to dissolve the analyte. The aliquot was filtered and transferred to an auto sampler vial for UPLC-MS/MS analysis.

\section{Liquid chromatography-tandem mass spectrometry determination}

The liquid chromatography analysis was performed on an ACQUITY UPLC System with an ACQUITY UPLC ${ }^{\circledR}$ BEH C 18 column $(50 \times 2.1 \mathrm{~mm} ; 1.7 \mu \mathrm{m}$ particle diameter $)$ from Waters (Massachusetts, USA) at $30^{\circ} \mathrm{C}$. Mobile phase component A was ultrapure water and component B was ACN, both with $0.1 \%$ formic acid. The optimized gradient used was $98 \%$ of phase A for $0.5 \mathrm{~min}$; then it decreased linearly by $70 \%$ of phase A until $2.0 \mathrm{~min} ; 50 \%$ A until
$3.0 \mathrm{~min}$; 30\% A until $4.0 \mathrm{~min}$; 2\% A until $5.0 \mathrm{~min}$ and maintained for $4 \mathrm{~min}$. Finally, phase A increased linearly until 10 min to achieve $98 \%$ of phase A.

The MS/MS measurements were performed in an ACQUITY TQD triple quadrupole mass spectrometer (Waters, MA, USA). The ionization source was an electrospray probe operated in positive mode. Acquisition was performed in multiple reaction monitoring (MRM) mode to obtain sufficient quantification points to confirm each analyte (CEFT, CLOX and ENRO). Ionization and mass spectrometric conditions were optimized for each AR by infusion at a flow rate of $5 \mu \mathrm{L} \mathrm{min}^{-1}$ using methanol:water (50:50/v:v) with $0.1 \%$ formic acid as mobile phase. The specific MS/MS parameters for each AR are shown in Table 1 . The following spectrometer parameters were similar for the three analytes: source temperature at $150^{\circ} \mathrm{C}$, capillary voltage of $2.0 \mathrm{kV}$, nitrogen as desolvation gas at a rate of $600 \mathrm{~L} \mathrm{~h}^{-1}$, nitrogen as nebulizer gas at a flow rate of $50 \mathrm{~L} \mathrm{~h}^{-1}$, desolvation temperature at $350{ }^{\circ} \mathrm{C}$ and argon was used as collision gas.

\section{Validation procedure}

The validation procedure was performed based on the Manual de Garantia de Qualidade Analítica, of Ministério da Agricultura, Pecuária e Abastecimento (MAPA). ${ }^{19}$ The evaluated parameters for quantitative methods were recovery (REC) and matrix effect (ME), selectivity, linearity, intraday and interday precision, accuracy, limits of detection (LODs) and limits of quantification (LOQs). The analytes included in the method comprise substances with different MRLs, thus, this study was based in the specific MRL of each drug. Concentration levels corresponding to $0.25 \times \mathrm{MRL}, 0.50 \times \mathrm{MRL}, 1.00 \times \mathrm{MRL}, 1.50 \times \mathrm{MRL}$ and $2.00 \times$ MRL were used (MRLs: $100 \mu \mathrm{g} \mathrm{L}^{-1}$ to ENRO and CEFT; $30 \mu \mathrm{g} \mathrm{L}{ }^{-1}$ to CLOX). ${ }^{20}$ The MRL for ENRO is based on the sum of enrofloxacin and its marker residue ciprofloxacin. Spiked pasteurized milk samples with CEFT, CLOX and ENRO were prepared using the stock solutions at various concentrations.

The REC and ME were evaluated using samples prepared in mobile phase (A), samples spiked with the standards after the extraction procedure (i.e., blank; B),

Table 1. Optimized values for the antibiotics residues (ARs)

\begin{tabular}{lcccccc}
\hline Antibiotics residues & Retention time / min & Precursor ion $(\mathrm{m} / \mathrm{z})$ & Product ion $^{\mathrm{a}}(\mathrm{m} / \mathrm{z})$ & Cone voltage $/ \mathrm{V}$ & Collision energy / eV & Dwell time / s \\
\hline Ceftiofur (CEFT) & $3.38-3.50$ & 524 & $210^{\mathrm{I}} ; 241^{\mathrm{Q}}$ & 30 & 20 & 0.180 \\
Cloxacillin (CLOX) & $4.36-4.46$ & 436 & $114^{\mathrm{I}} ; 160^{\mathrm{Q}}$ & 20 & 30 & 0.180 \\
Enrofloxacin (ENRO) & $2.44-2.53$ & 360 & $245^{\mathrm{Q}} ; 316^{\mathrm{I}}$ & 20 & 30 & 0.180 \\
\hline
\end{tabular}

${ }^{\mathrm{a}} \mathrm{Q}$ : transition used for quantification; I: transition employed to complete the identification. 
and samples spiked with the standards (C), all at the MRLs levels and in triplicates. ${ }^{21}$ REC and ME were calculated as proposed by Matuszewski et al. ${ }^{22}$ using the following equations:

$$
\begin{aligned}
& \operatorname{ME}(\%)=\left(\frac{B}{A}\right) 100 \\
& \operatorname{REC}(\%)=\left(\frac{C}{B}\right) 100
\end{aligned}
$$

The selectivity was evaluated using raw milk samples obtained from various dairy farms in Paraná State (Brazil) with different fat levels, in a total of 91 samples.

Linearity was analyzed using calibration curves prepared by matrix overlap at concentrations of $0.25,0.5$, 1.0, 1.5 and $2.0 \times$ MRLs. Three calibration curves were prepared for three different days and the linearity was evaluated by linear regression using the coefficient of determination $\left(\mathrm{R}^{2}\right)$.

Accuracy and precision were assessed by recovery using spiked samples (six replicates on three different days) at concentrations of $0.5,1.0$ and $1.5 \times$ MRLs. Precision was assessed through repeatability (intraday precision) and reproducibility (interday precision) and relative standard deviations (RSD) were calculated for both. ${ }^{19}$

The LOD and LOQ were determined by the mean of the signal-to-noise ratio, in which the signal must be three times higher than the noise for LOD and ten times higher for the LOQ. For this experiment, dilutions of blank spiked with standards were considered.

\section{Experimental design to optimize the modified QuEChERS}

A full factorial design was used to evaluate the effects and optimize three variables of the sample preparation method using the QuEChERS described by Wang et al. ${ }^{18}$ The three variables were chosen for the dispersive SPE clean-up step: the amounts of anhydrous C18, PSA, and $\mathrm{NaAc}$. The MRLs were considered for method validation. A two level with three independent variables with six replicates at the central point full factorial design was performed using the software Statistica. ${ }^{23}$ The chemicals for the clean-up step C18, PSA and anhydrous NaAc, and the amounts of the chemicals for the clean-up step in the ranges of 50-150 mg, 25-75 mg, and 0.5-1.5 g, respectively, were used. The peak areas were used as the response to determine the optimal conditions for the sample preparation methods of the ARs. The design consisted of 14 experiments and six replications of the central point (Table S1, Supplementary Information (SI) section).

\section{Results and Discussion}

\section{Optimization of MS/MS and chromatographic separation}

The mass spectrometer was optimized to provide the best responses for the quantification of CEFT, CLOX and ENRO (Table 1). Each AR was characterized by the retention time and by two precursors-product ion transitions. The most abundant ion produced was used for quantification, whereas the second most abundant was used to complete the identification. With respect to the chromatographic conditions, the gradient elution was studied to determine the best separation, peak shape and sensitivity in the shortest time. Figure 1 shows the MRM transitions for each residue.

Experimental design and optimized conditions for each antibiotic

The extraction of ARs was optimized using a complete factorial design. In the planning, 14 experiments were conducted in triplicates with different concentrations of C18, PSA and NaAc. The analysis of variance (ANOVA) was performed with data collected from the experiments with a confidence interval of $95.0 \%$.

The proposed model for this study was significant with $\mathrm{R}^{2}$ determination coefficient appropriate to the model adequacy. In this study, the $\mathrm{R}^{2}$ coefficients for ENRO, CEFT and CLOX were, respectively: 0.9844 or $98.44 \%$; 0.9865 or $98.65 \%$; 0.9707 or $97.07 \%$. The coefficients indicate that about $1.56 \%$ of the variations for ENRO were not determined by the model, the same can be said for $1.35 \%$ of the variations of CEFT and $2.93 \%$ of the variations of CLOX. The adjusted $\mathrm{R}^{2}\left(\mathrm{R}^{2}\right.$ adj) coefficients for ENRO, CEFT and CLOX were respectively: 0.9710 or $97.10 \% ; 0.9749$ or $97.49 \%$; 0.9456 or $94.56 \%$. The coefficients $\mathrm{R}^{2}$ adj propose that the model was highly significant for the simultaneous extraction of the three antibiotics studied.

The amount of NaAc was the factor that most affected the extraction of the three residues (with $p$ value from 0.000012 to 0.00017 ), showing a negative effect, that is, showing to be optimal at low levels, probably due to ion suppression. Ion suppression alters droplet formation efficiency or droplet evaporation, which, in turn, affects the amount of charged ions in the gas phase causing a loss of signal. ${ }^{24}$ For ENRO, factor C18 was significant and had negative effects, with $p$ value $=0.00005$. For CLOX, the amount of PSA was also a significant factor in the extraction process ( with $p$ value $=0.047$ ), in which it presented a better response at low levels. 
(a)

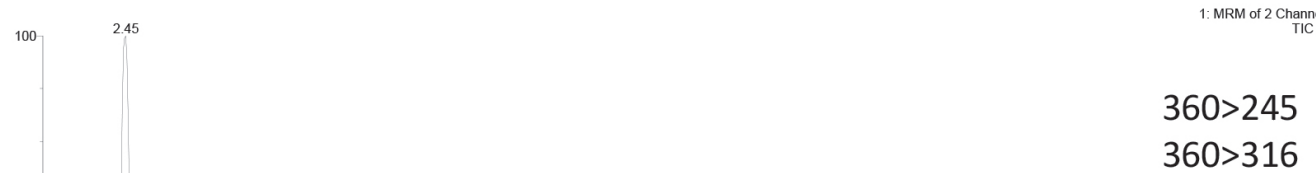

(b)

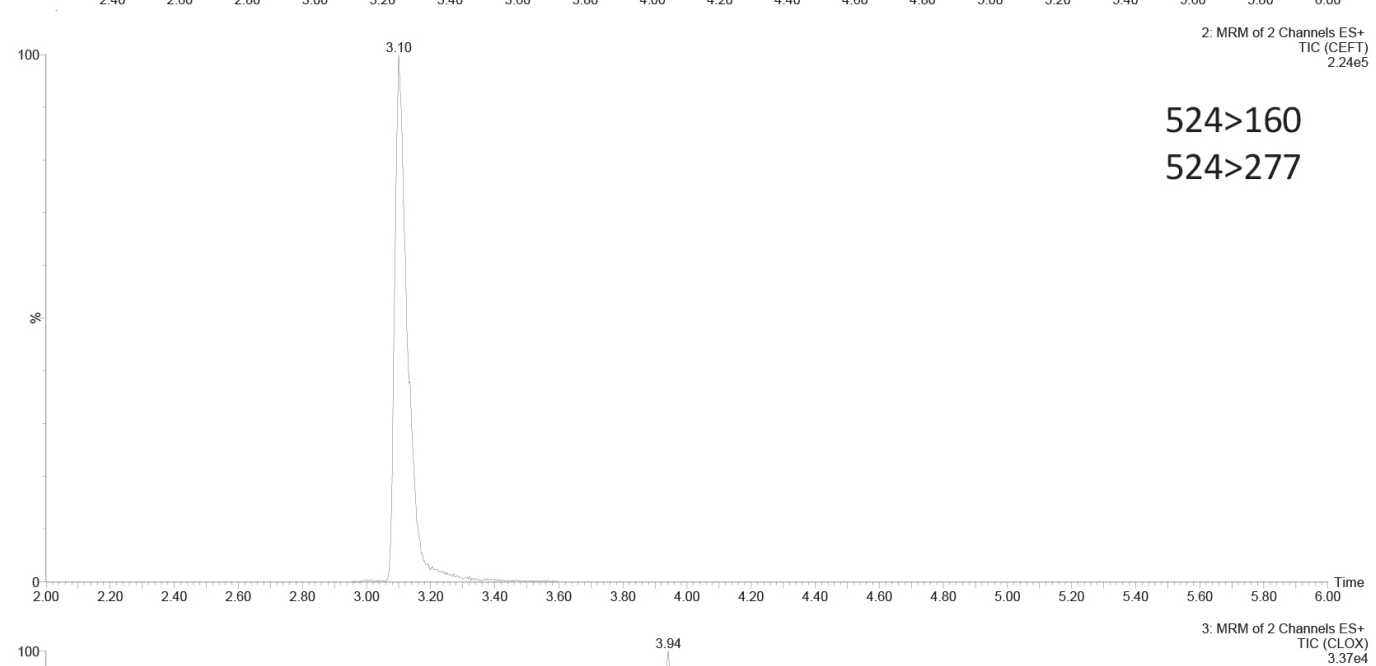

(c)

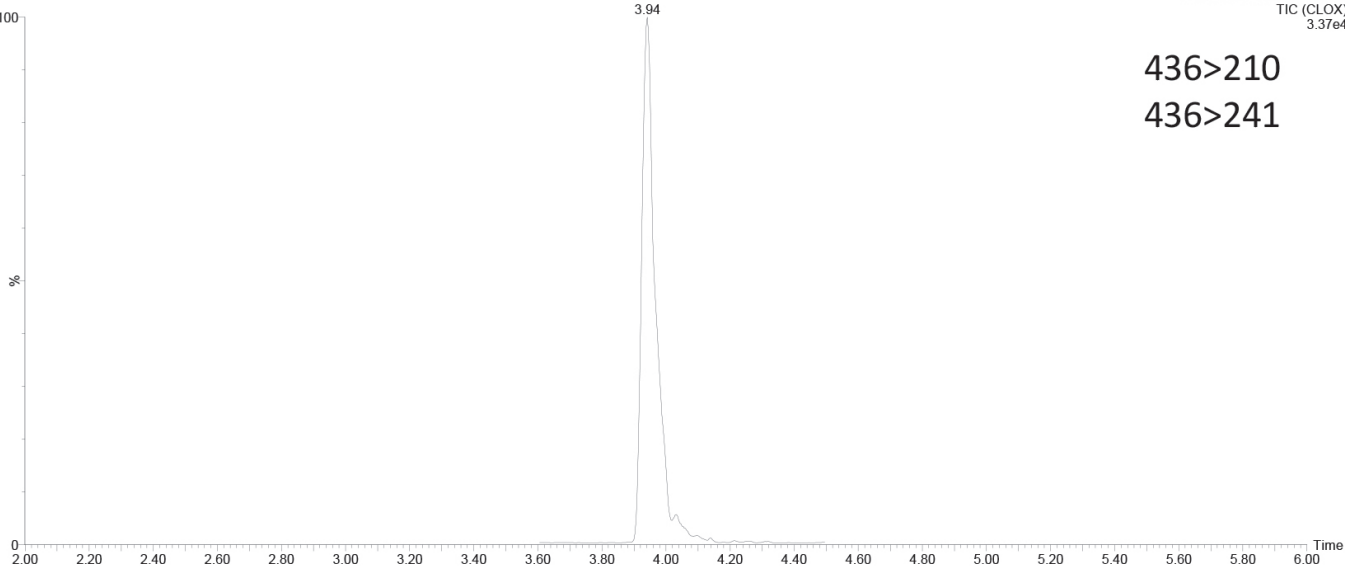

Figure 1. MRM chromatograms of a spiked milk samples with (a) enrofloxacin at $100 \mu \mathrm{g} \mathrm{L}^{-1}$; (b) ceftiofur at $100 \mu \mathrm{g} \mathrm{L}{ }^{-1}$ and (c) cloxacillin at $30 \mu \mathrm{g} \mathrm{L}{ }^{-1}$.

The model also showed that curvature was a significant term in the extraction of the three antibiotics shown, with $p$ value from 0.000083 to 0.00069 ; however, the predicted model is highly suitable with acceptable $\mathrm{R}^{2}$ and $R^{2}$ adj coefficients, hence the terms of curvature can be ignored.

The best conditions of the three reagents (C18, PSA and $\mathrm{NaAc}$ ) for the drug residues were $50.0 \mathrm{mg} \mathrm{C} 18$, $25.0 \mathrm{mg}$ PSA and $0.5 \mathrm{~g} \mathrm{NaAc}$ (Figure 2). The maximum value predicted by the complete factorial design was set for subsequent analysis, including REC and ME, set out in Table 2.

Because of the different structure, polarity, chemical and physical properties of each antibiotic, the optimized factors produce different responses for each sample, thus explaining the importance of multivariate optimization in an extraction process to know the best experimental conditions for the method in different matrices. 
(a)

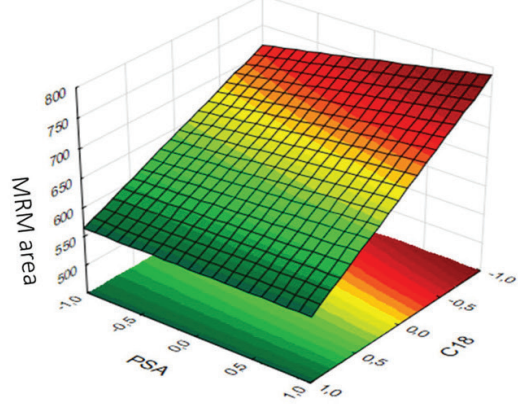

(b)

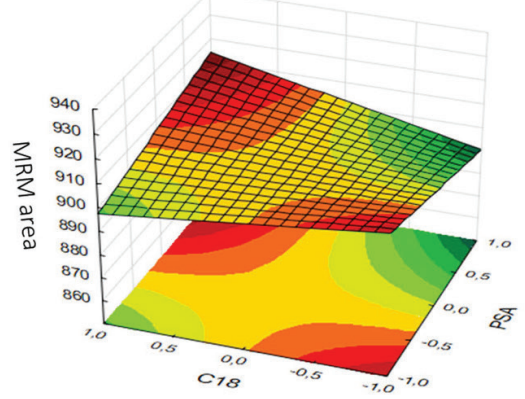

(c)

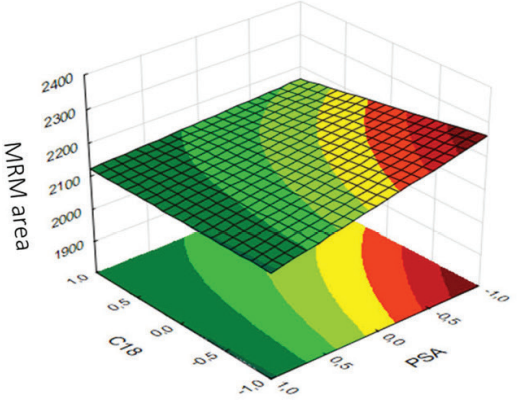

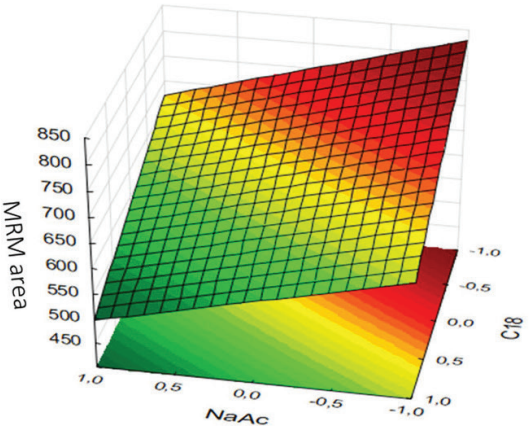
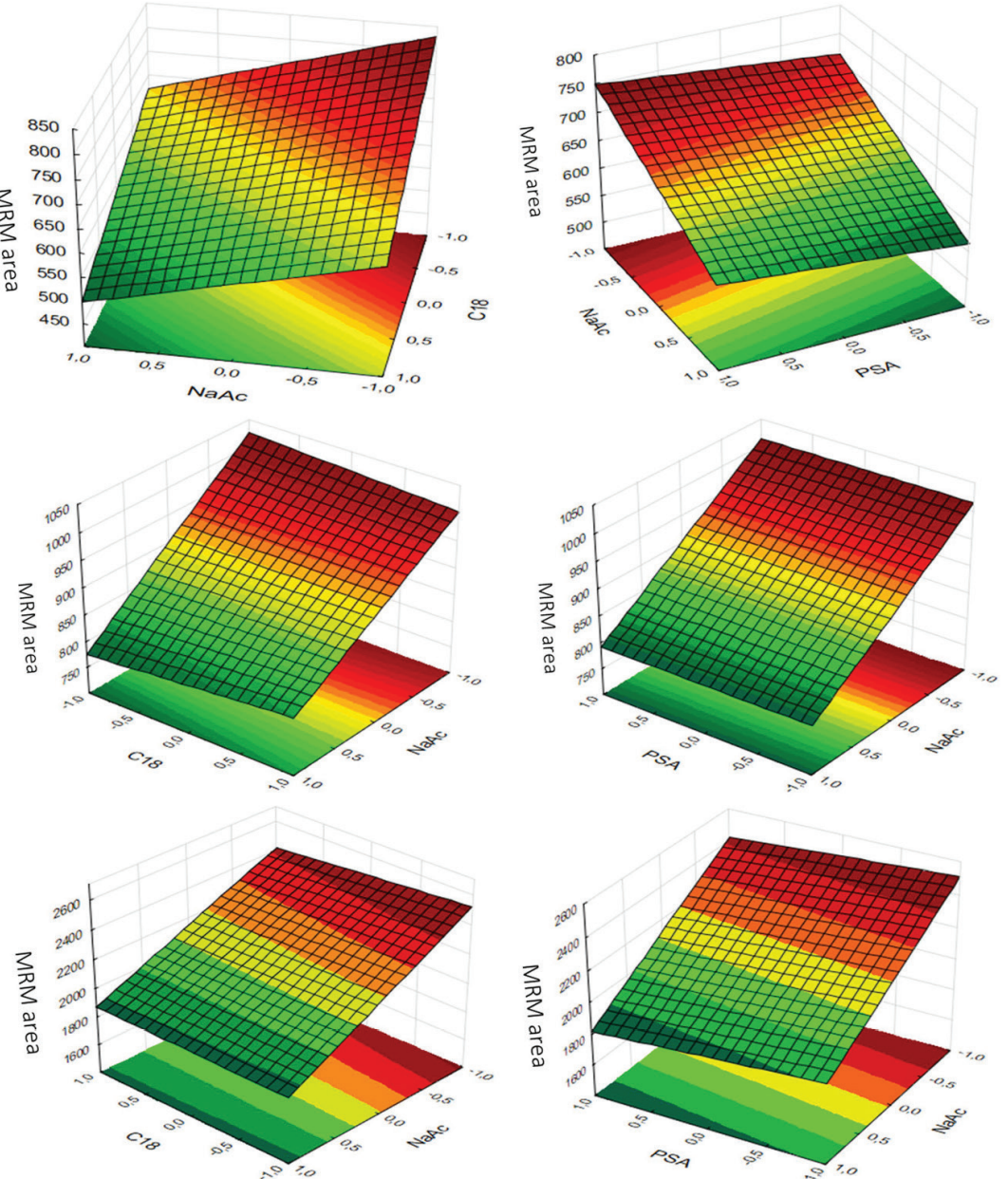

Figure 2. Response surface maps of the area of the quantification of (a) cetftiofur; (b) cloxacillin and (c) enrofloxacin for different amounts of C18, PSA and NaAc.

Table 2. Recovery (REC) of the different QuEChERS and matrix effect (ME) of optimized QuEChERS for the antibiotics residues

\begin{tabular}{lccc}
\hline \multirow{2}{*}{$\begin{array}{l}\text { Antibiotic } \\
\text { residue }\end{array}$} & \multicolumn{2}{c}{ Optimized QuEChERS } & $\begin{array}{c}\text { QuEChERS } \\
\text { acetate }\end{array}$ \\
\cline { 2 - 4 } & REC / \% & ME / \% & REC / \% \\
\hline CEFT & 99 & 98 & 53 \\
CLOX & 95 & 138 & 73 \\
ENRO & 98 & 89 & 3 \\
\hline
\end{tabular}

QuEChERS: quick, easy, cheap, effective, rugged and safe; CEFT: ceftiofur; CLOX: cloxacillin; ENRO: enrofloxacin.

\section{Comparison between QuEChERS methods and validation}

The QuEChERS (acetate and optimized) methods were compared evaluating the REC values of the antibiotics, as shows Table 2. The QuEChERS acetate proved to be inefficient in extracting the antibiotics studied. The residues of CEFT and CLOX had low recovery and it was not possible to extract ENRO. Acceptable recovery ranges for residue analysis are generally between 70 and $120 \% .{ }^{25}$ The optimized QuEChERS was more efficient in the extraction of all the antibiotics studied, with recovery values above $95 \%$. Thus, this method was chosen for future experiments of validation.

Table 2 also shows the ME of the optimized QuEChERS. No increase or suppression of signal has been observed for CEFT, so the ionization of this is not affected by the matrix. For the ENRO residue, ion suppression was observed and there was appreciation in the ionization for CLOX. An ME value above $100 \%$ is considered a signal enhancement, while ME below $100 \%$ is considered a signal suppression. The most frequent approach to avoid or minimize the matrix effect is the use of calibration curve prepared using blank matrices (matrix superposition). ${ }^{26}$

Linearity was established by linear regression analysis of the calibration curves prepared on three different days. The regression equation for each analyte was established by plotting the area of the peak (y) compared to the concentration $(x)$ studied from the blank to $2.0 \times$ MRL. The 
Table 3. Intraday and interday precision and accuracy for each antibiotic residue

\begin{tabular}{|c|c|c|c|c|c|c|c|c|c|}
\hline \multirow{2}{*}{$\begin{array}{l}\text { Antibiotic } \\
\text { residue }\end{array}$} & \multicolumn{3}{|c|}{$\begin{array}{l}\text { Intraday precision } \\
(\mathrm{REC} \pm \mathrm{RSD}) / \%\end{array}$} & \multicolumn{3}{|c|}{$\begin{array}{l}\text { Interday precision } \\
(\mathrm{REC} \pm \mathrm{RSD}) / \%\end{array}$} & \multicolumn{3}{|c|}{ Accuracy (REC) / \% } \\
\hline & $0.5 \mathrm{MRL}$ & 1.0 MRL & $1.5 \mathrm{MRL}$ & $0.5 \mathrm{MRL}$ & $1.0 \mathrm{MRL}$ & 1.5 MRL & $0.5 \mathrm{MRL}$ & 1.0 MRL & $1.5 \mathrm{MRL}$ \\
\hline CEFT & $102 \pm 7.4$ & $98 \pm 1.7$ & $97 \pm 6.6$ & $107 \pm 10.4$ & $100 \pm 11.8$ & $95 \pm 12.4$ & 98 & 98 & 91 \\
\hline CLOX & $105 \pm 4.4$ & $98 \pm 7.8$ & $103 \pm 6.4$ & $101 \pm 6.9$ & $103 \pm 10.3$ & $98 \pm 8.4$ & 99 & 99 & 99 \\
\hline ENRO & $100 \pm 8.8$ & $92 \pm 12.3$ & $92 \pm 3.3$ & $108 \pm 8.1$ & $90 \pm 4.9$ & $98 \pm 7.6$ & 92 & 97 & 98 \\
\hline
\end{tabular}

REC: recovery; RSD: relative standard deviation; MRL: maximum residue limit; CEFT: ceftiofur; CLOX: cloxacillin; ENRO: enrofloxacin.

determination coefficients $\left(\mathrm{R}^{2}\right)$ were above 0.96 (Table S2, SI section). The statistical evaluation of the regression residuals was performed, in which we obtained values of up to $17.0 \%$ for the concentrations below the MRL for ENRO and 2.5\% for the remaining concentrations. The residual values for CEFT had a maximum value of $3.6 \%$, whereas for CLOX, the values were below $8.0 \%$. According to the Manual de Garantia de Qualidade Analítica, ${ }^{19}$ the residues should not exceed $\pm 20 \%$ at concentrations below the MRL and $\pm 10 \%$ at the MRL and above.

For the interday precision conditions, the RSD must typically be below $20 \%$ for concentrations between 10 and $100 \mu \mathrm{g} \mathrm{L}{ }^{-1}$, and below $15 \%$ for concentrations above $100 \mu \mathrm{g} \mathrm{L}^{-1}$ to $1 \mathrm{mg} \mathrm{L}^{-1}$, and to intraday precision the relative standard deviations (RSD) should typically be less than two-thirds of the values presented. Results calculated using RSD for intraday and interday precision were lower than $12.4 \%$ (Table 3). The RSD obtained are in accordance with Manual de Garantia de Qualidade Analítica. ${ }^{19}$ In the absence of certified reference material, accuracy was determined by fortification of blank samples and was calculated by the REC test of each residue at the levels studied $(0.5,1.0$ and $1.5 \times$ MRL). The results obtained were above $91 \%$ for all analytes.

The sensitivity of the method was determined by LOD and LOQ for each drug (Table 4).

Table 4. Maximum residue limit (MRL), limit of detection (LOD) and limit of quantification (LOQ) for each antibiotic residue

\begin{tabular}{lccc}
\hline $\begin{array}{l}\text { Antibiotic } \\
\text { residue }\end{array}$ & MRL / $\left(\mu \mathrm{g} \mathrm{L}^{-1}\right)$ & $\mathrm{LOD} /\left(\mu \mathrm{g} \mathrm{L}^{-1}\right)$ & $\mathrm{LOQ} /\left(\mu \mathrm{g} \mathrm{L}{ }^{-1}\right)$ \\
\hline CEFT & 100 & 1.4 & 1.5 \\
CLOX & 30 & 4.9 & 5.3 \\
ENRO & 100 & 6.8 & 8.7 \\
\hline
\end{tabular}

CEFT: ceftiofur; CLOX: cloxacillin; ENRO: enrofloxacin.

\section{Samples analysis}

Samples of raw milk $(n=91)$ were processed using the validated method to provide confirmatory and quantitative analysis, only 7 of them had any of the antibiotics studied. ENRO was found in 6 analyzed samples, all below LOQ. Only one sample presented ENRO below the LOQ and CEFT, at a concentration of $5.59 \mu \mathrm{g} \mathrm{L}^{-1}$. Only $7.69 \%$ of the analyzed milk samples had any of the antibiotics analyzed under the MRL, all were in accordance with the legislation. ${ }^{20}$ Ciprofloxacin, the biomarker of ENRO, was also monitored by MRM and was not found in the milk samples analyzed.

The method used seemed to be quite adequate as it is based on UPLC-MS/MS, and confirms and quantifies only suspect samples, however, it should be noted that the method was used for the analysis of the active principle ceftiofur and may not be suitable for its marker residue, desfuroylceftiofur.

\section{Conclusions}

The optimized QuEChERS method proved to be very efficient in extracting the antibiotics ENRO, CEFT and CLOX in a complex matrix such as dairy milk and was fully validated for confirmatory and quantitative purposes. It presented simplicity and applicability, fundamental characteristics for routine methods in food control, and will certainly contribute to the investigation and control of the quality of dairy milk as well as to assist the producers of dairy cattle in the best management of veterinary medicines.

\section{Supplementary Information}

Supplementary data are available free of charge at http://jbcs.sbq.org.br as PDF file.

\section{Acknowledgments}

The authors would like to thank CAPES for financial support.

\section{References}

1. O'Neill, J.; Review on Antimicrob. Resistence 2016, available at https://amr-review.org/sites/default/files/160518_Final\%20 paper_with\%20cover.pdf, accessed in September 2018. 
2. Marshall, B. M.; Levy, S. B.; Clin. Microbiol. Rev. 2011, 24, 718.

3. The State of the World's Antibiotics, 2015, available at https:// cddep.org/wp-content/uploads/2017/06/swa_edits_9.16.pdf, accessed in April 2018.

4. McEwen, S. A.; Fedorka-Cray, P. J.; Clin. Infect. Dis. 2002, 34, S93.

5. Fonseca, G. P.; Cruz, A. G.; Faria, J. A. F.; Silva, R.; Moura, M. R. L.; Carvalho, L. M. J.; Ciênc. Tecnol. Aliment. 2009, 29, 452.

6. Zootechnical Report Zoetis; Residues of Antimicrobial Products: Zero Discard x Zero Residue; available at http:// iqmax.com.br/asset/library/Boletim\%20T\%C3\%A9cnico\% 2003.pdf, accessed in November 2018.

7. Lord, H.; Pawliszyn, J.; J. Chromatogr. A 2000, 902, 17.

8. Anastassiades, M.; Lehotay, S. J.; J. AOAC Int. 2003, 86, 412.

9. Rejcak, T.; Tuzimski, T.; J. AOAC Int. 2015, 98, 1143.

10. Lehotay, S. J.; Maòtovská, K.; Yun, S. J.; J. AOAC Int. 2005, $88,630$.

11. Kahn, C. M.; Line, S.; The Merck Veterinary Manual, $9^{\text {th }}$ ed.; Merck \& Co.: New Jersey, USA, 2005.

12. Empresa Brasileira de Pesquisa Agropecuária (EMBRAPA); Indicadores Leite e Derivados, available at https://ainfo. cnptia.embrapa.br/digital/bitstream/item/179503/1/2018-07Indicadores-leite.pdf, accessed in September 2018., accessed in September 2018.

13. Instituto Brasileiro de Geografia e Estatística (IBGE); Estatística da Produção Pecuária, available at https://biblioteca. ibge.gov.br/visualizacao/periodicos/3087/epp_pr_2018_1tri. pdf, accessed in May 2018.

14. Empresa Brasileira de Pesquisa Agropecuária (EMBRAPA); Programa do Leite, available at https://www.embrapa. br/documents/1355117/1528925/Panorama+do+Leite++outubro+2015/f97da482-483f-4451-bd26-e9f7e1d95c4b, accessed in September 2018.
15. Dias, S. L.; Fujiwara, S. T.; Gushikem, Y.; Bruns, R. E.; J. Electroanal. Chem. 2002, 531, 141.

16. Ferreira, S. C.; Bruns, R.; Ferreira, H.; Matos, G.; David, J.; Brandao, G.; da Silva, E. P.; Portugal, L.; dos Reis, P.; Souza, A.; Anal. Chim. Acta 2007, 597, 179.

17. El Atrache, L. L.; Sghaier, R. B.; Kefi, B. B.; Haldys, V.; Dachraoui, M.; Tortajada, J.; Talanta 2013, 117, 392.

18. Wang, Y.; Liu, Z.; Ren, J.; Guo, B.; Foodborne Pathog. Dis. 2015, 12, 693.

19. Ministério da Agricultura, Pecuária e Abastecimento (MAPA); Secretaria de Defesa Agropecuária (SDA); Manual de Garantia da Qualidade Analítica, $1^{\text {a }}$ ed.; MAPA: Brasília, 2011.

20. Ministério da Agricultura, Pecuária e Abastecimento (MAPA); Instrução Normativa No. 09, de 21/02/2017; DOU: 08/03/2017, available at http://www.agricultura.gov.br/assuntos/inspecao/ produtos-animal/plano-de-nacional-de-controle-de-residuos-econtaminantes/documentos-da-pncrc/pncrc-2017.pdf, accessed in November 2018.

21. Hoff, R. B.; Rübensam, G.; Jank, L.; Barreto, F.; Peralba, M. C. R.; Pizzolato, T. M.; Días-Cruz, S.; Barceló, D.; Talanta 2014, $132,443$.

22. Matuszewski, B. K.; Constanzer, M. L.; Chavez-Eng, C. M.; Anal. Chem. 2003, 75, 3019.

23. Statistica 7.0; StatSoft, Tulsa, OK, USA, 2004.

24. Annesley, T. M.; Clin. Chem. 2003, 49, 1041.

25. Ribane, M.; Bottoli, C. B. G.; Collins, C. H.; Jardim, I. C. S. F.; Melo, L. F. C.; Quim. Nova 2004, 5, 771.

26. Martins, M. T.; Barreto, F.; Hoff, R. B.; Jank, L.; Arsand, J. B.; Motta, T. M. C.; Schapoval, E. E. S.; Int. Dairy J. 2016, 59, 44.

Submitted: October 14, 2018 Published online: March 26, 2019 